\title{
CONSTRUÇÃO DE UMA CÂMARA DE CURA PILOTO COM ALIMENTAÇÃO A VAPOR PARA PRODUÇÃO DE PLACAS DE BATERIAS DE CHUMBO-ÁCIDO
}

\section{CONSTRUCTION OF A PILOT CURE CHAMBER WITH STEAM FEEDING FOR LEAD ACID BATTERIES PLATES PRODUCTION}

\author{
B. G. DALVI ${ }^{1}$, K. C. SANTOS ${ }^{1}$, L. C. SANTANA ${ }^{2, *}$, C. M. de CARVALHO ${ }^{3}$ e G. A. O. BRITO ${ }^{4}$
}

${ }^{1}$ Institute of Technology Edson Mororó Moura, Belo Jardim, Pernanbuco, Brazil

${ }^{2}$ Federal University of Espírito Santo, Department of Rural Engineering, Alegre, Espírito Santo, Brazil

${ }^{3}$ Federal University of Espírito Santo, Postgraduate Program in Chemical Engineering, Alegre, Espírito Santo, Brazil

${ }^{4}$ Federal University of Uberlândia, Department of Chemistry, Uberlândia, Minas Gerais, Brazil

${ }^{*}$ Corresponding author. Federal University of Espirito Santo, Department of Rural Engineering, Alegre, Espírito Santo, Brazil, Phone: +5528998816761

e-mail addressl: lucascarvalhosantana@outlook.com.br (L. C. Santana).

\begin{tabular}{|c|}
\hline A R T I C LE I N F O \\
\hline $\begin{array}{l}\text { Article history: } \\
\text { Received 2020-06-30 } \\
\text { Accepted 2020-10-20 } \\
\text { Available online 2020-10-20 }\end{array}$ \\
\hline $\begin{array}{l}\text { palavras-chave } \\
\text { Baterias de chumbo-ácido } \\
\text { Câmara de cura } \\
\text { Arduino }\end{array}$ \\
\hline $\begin{array}{l}\frac{k e y w o r d s}{\text { Lead Acid Batteries }} \\
\text { Cure Chamber } \\
\text { Arduino }\end{array}$ \\
\hline
\end{tabular}

\section{A B S T R A C T}

In the production of lead-acid batteries, the main step is the curing process of pasted plates. Although there are studies dealing with the healing process, mainly with the objective of optimizing the stage and improving the performance of the batteries, there is a need for a systematic study of this process. Thus, the main objective of this work is the construction of a pilot scale equipment with humidity and temperature control, more commonly known in the sector as a curing chamber. With this, the intention is to operate it in different conditions from variations in humidity and temperature, which directly influences the properties of the precursor material obtained after the curing step. The constructed pilot presented satisfactory results, being important for the study of the influence of humidity and temperature with the characteristics of the precursor material.

R E S U M O

Na produção de baterias chumbo-ácido, a etapa principal é o processo de cura de placas empastadas. Embora haja estudos tratando do processo de cura, principalmente com os objetivos de otimizar a etapa e melhorar o desempenho das baterias, existe a necessidade de um estudo sistematizado deste processo. Deste modo o principal objetivo deste trabalho é a construção de um equipamento em escala piloto com controle de umidade e temperatura, mais comumente conhecido no setor como câmara de cura. Com isso, tem-se o intuito de operá-la em diferentes condições a partir das variações de umidade e temperatura, que influencia diretamente nas propriedades do material precursor obtido após a etapa de cura. O piloto construído apresentou resultados satisfatórios, sendo, portanto, de grande valia para o estudo da influência da umidade e temperatura com as características do material precursor. 


\section{INTRODUÇÃO}

Após a descoberta da eletricidade e o desenvolvimento tecnológico, sistemas confiáveis de acúmulo de energia vêm sendo utilizados em larga escala. Dentre os acumuladores de energia existentes, a bateria chumbo ácido se destaca por ser um dos mais antigos tipos de baterias comerciais conhecidos pela indústria e por gerar grandes receitas. Em função da sua importância tecnológica e econômica, das novas demandas e da concorrência com outras tecnologias de baterias secundárias, tem havido uma intensa atividade de pesquisa para o desenvolvimento da bateria chumbo-ácido a nível mundial.

Apesar do desenvolvimento de modelos a fim de interpretar o funcionamento desses acumuladores de energia, os quais permitem o controle das características iniciais das baterias e a determinação das características relacionadas com o processo de produção (PALMER, 2008), há diversos mecanismos envolvidos nas diferentes etapas da produção que ainda não são totalmente compreendidos. Exemplos são a relação entre a composição, temperatura e umidade no processo de cura e a relação desses parâmetros com a forma e o tamanho das partículas formadas, além da cinética de crescimento de cristais e a conectividade desses componentes (FOXWORTHY, 1988).

Neste sentido, o presente trabalho busca contribuir para o estudo das etapas de produção de baterias de chumbo-ácido, mais especificamente o estudo da etapa de cura. Com isso, este trabalho objetiva a construção de uma câmara de cura piloto com alimentação a vapor, que engloba o controle de umidade e temperatura para o processo de cura das placas de baterias de chumbo-ácido.

\section{MATERIAIS E MÉTODOS}

\subsection{Construção da Estrutura da Câmara de Cura}

Na montagem da estrutura física, utilizou-se o polímero polipropileno, devido a fácil obtenção e propriedades físicas e químicas adequadas aos testes. A estrutura conta com uma parte cilíndrica, e uma parte cônica, unidas com fita asfáltica.

A estrutura conta com um cooler na parte inferior o qual é responsável por direcionar o fluxo de ar do meio externo para dentro da câmara, e a um cooler na parte superior, que direciona o fluxo de ar e vapor de dentro da câmara para o meio externo. Para a geração de vapor, utilizou-se uma resistência elétrica imersa em 3 litros de água destilada. Na parte superior da estrutura, foi posicionado um sensor de temperatura e umidade DHT22, o qual era fixado a tampa da câmara.

\subsection{Controle de Temperatura e Umidade}

Para o controle de umidade e temperatura, foi necessário a montagem de circuitos eletrônicos/elétricos utilizando-se uma placa Arduino versão UNO (hardware) associado ao programa Arduino 1.0.6 (software).

Na Figura 1, é apresentado o circuito para a conexão do display LCD a placa Arduino, responsável pela exibição dos valores de temperatura e umidade programada pelo operador. Os fios verdes e vermelhos representam, respectivamente, as ligações ao fio de aterramento e a fonte de alimentação de $5 \mathrm{~V}$.

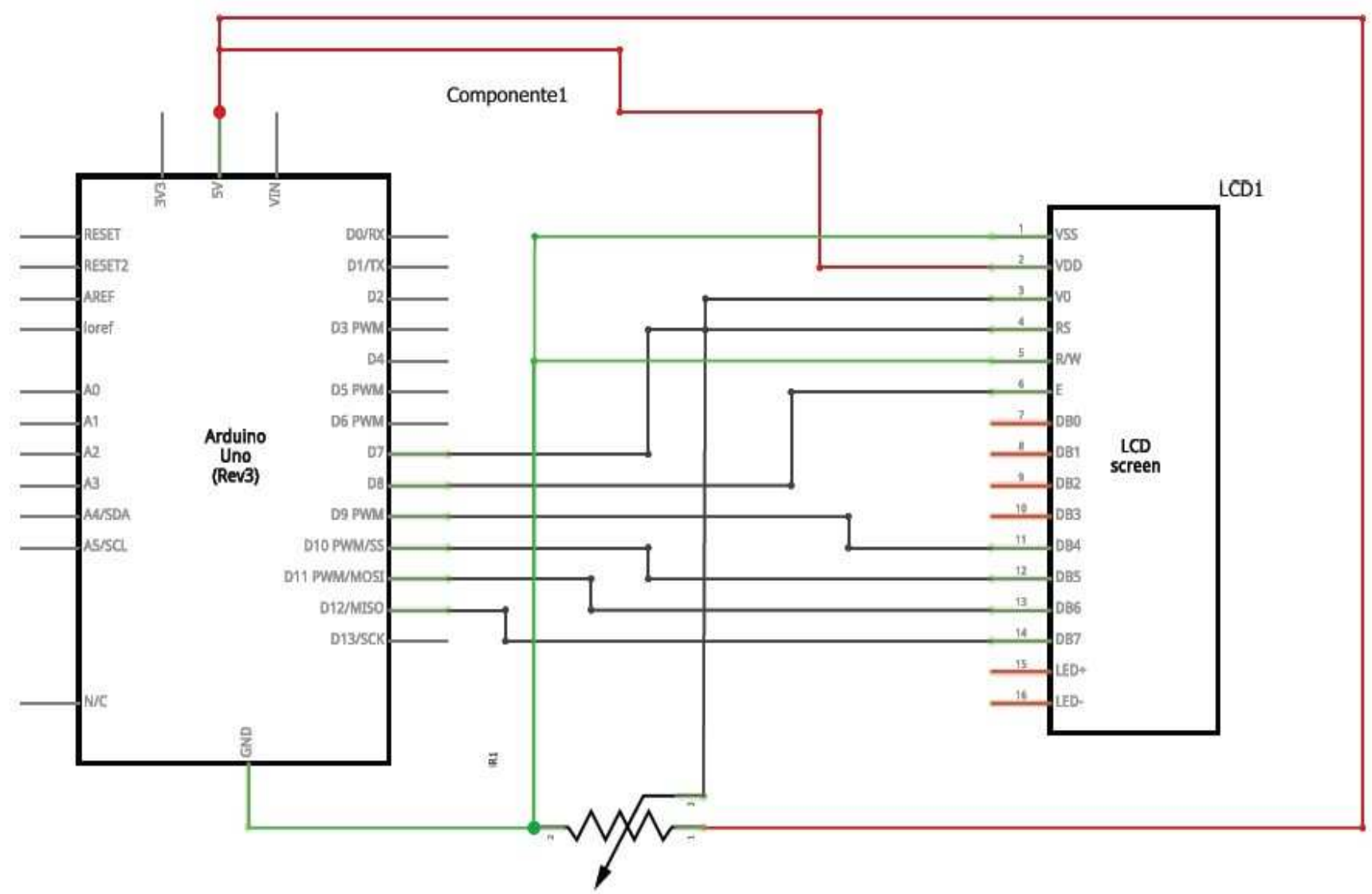

Figure 1 - Esquema do circuito para conexão do display a placa Arduino. (Fonte: Os autores). 
Na Figura 2 tem-se as conexões do sensor DHT22 a placa Arduino. Um resistor de $10 \mathrm{~K} \Omega$ foi utilizado no pino de dados do sensor como resistor pull-up, garantindo um nível lógico válido quando os pinos analógicos $\mathrm{A} 1$ da placa Arduino. O pino VCC é ligado a fonte de alimentação de $5 \mathrm{~V}$ da placa. Já o pino GND foi ligado ao aterramento (GND) da placa.

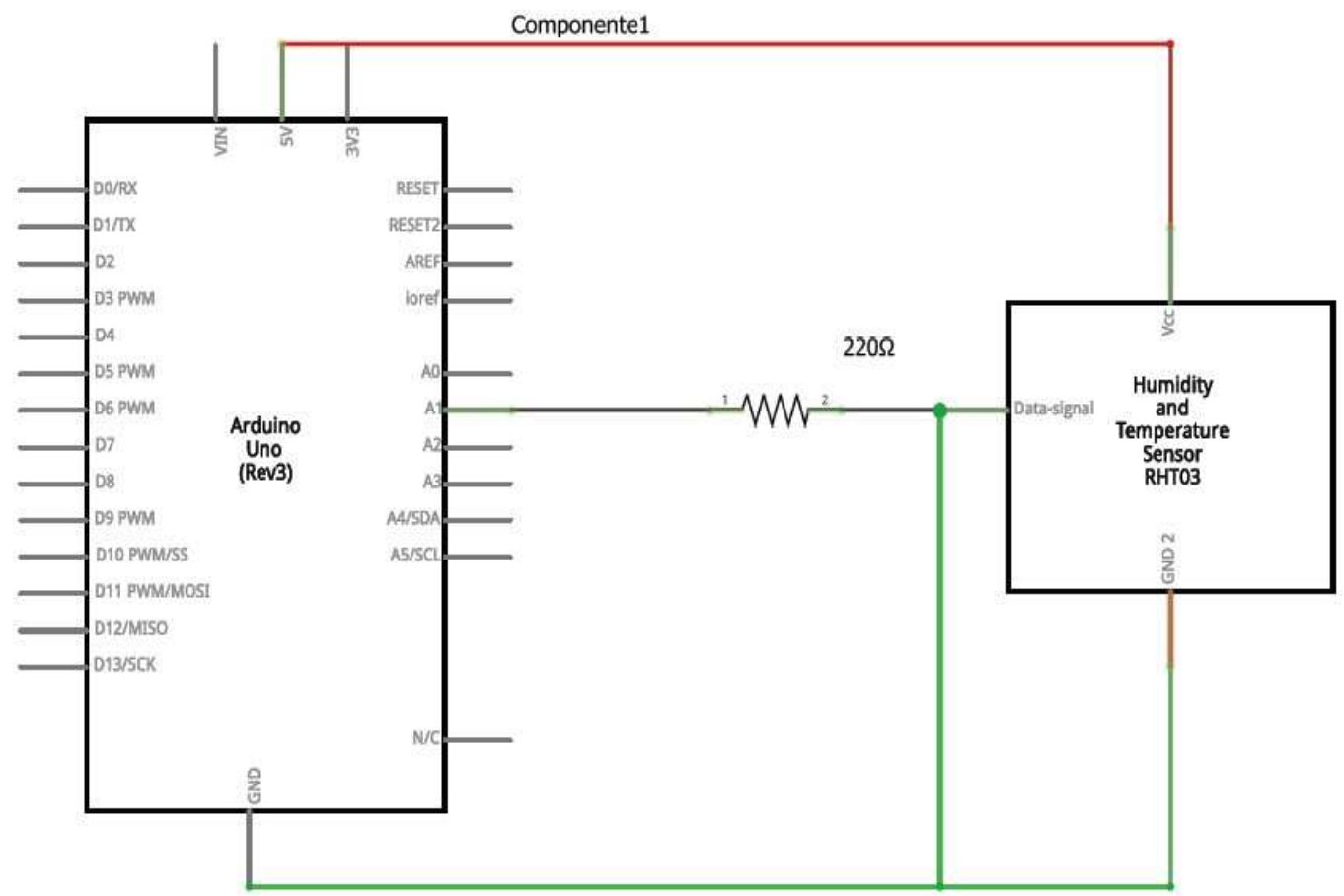

Figure 2 - Esquema do circuito para conexão do sensor DHSS. (Fonte: Os autores)

O circuito exibido na Figura 3, é responsável pelo acionamento da resistência elétrica. O pino 13/SCK está conectado por meio de um resistor R1 $(220 \Omega)$ a base do transistor Q1 (NPN 4001). O emissor do transistor está conectado ao terra, e o coletor está conectado a um dos terminais de controle da bobina do relé de voltagem $5 \mathrm{~V}$. O segundo terminal da bobina do relé está conectado a fonte de alimentação de 5V da placa Arduino. A resistência elétrica (Q3) está ligada a uma fonte externa de energia e ao relé (Q2).

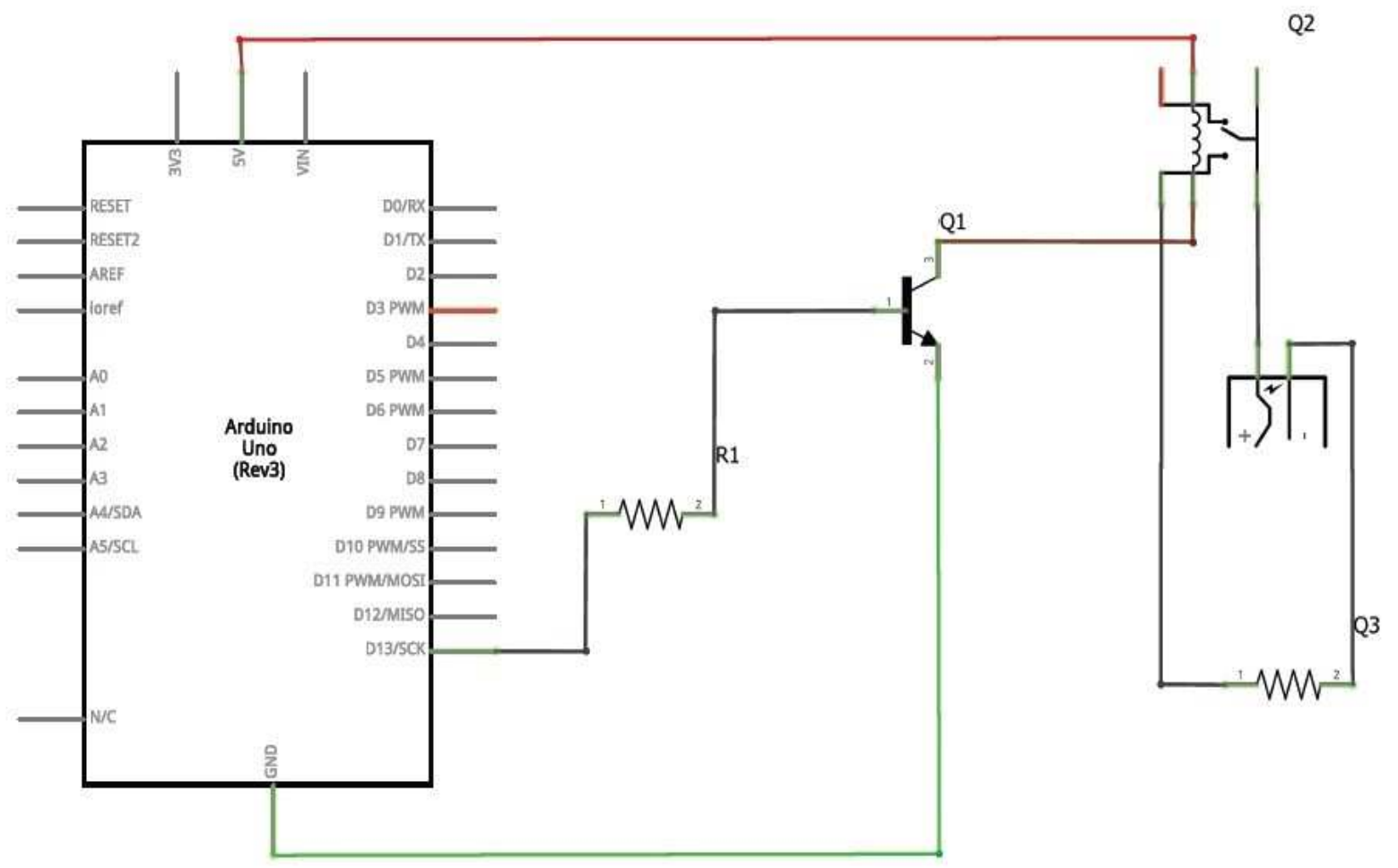

Figure 3 - Esquema do circuito para conexão da resistência elétrica. (Fonte: Os autores) 
A Figura 4 representa o circuito responsável pelo acionamento dos coolers (Q3), que foram conectados em paralelo. Suas conexões seguem o mesmo procedimento descrito para o circuito da resistência elétrica do parágrafo anterior, porém, neste caso, o pino GND está conectado por meio de um resistor R1 (220 $\Omega$ ) ao pino base 1 do transistor Q1 (NPN 4001).

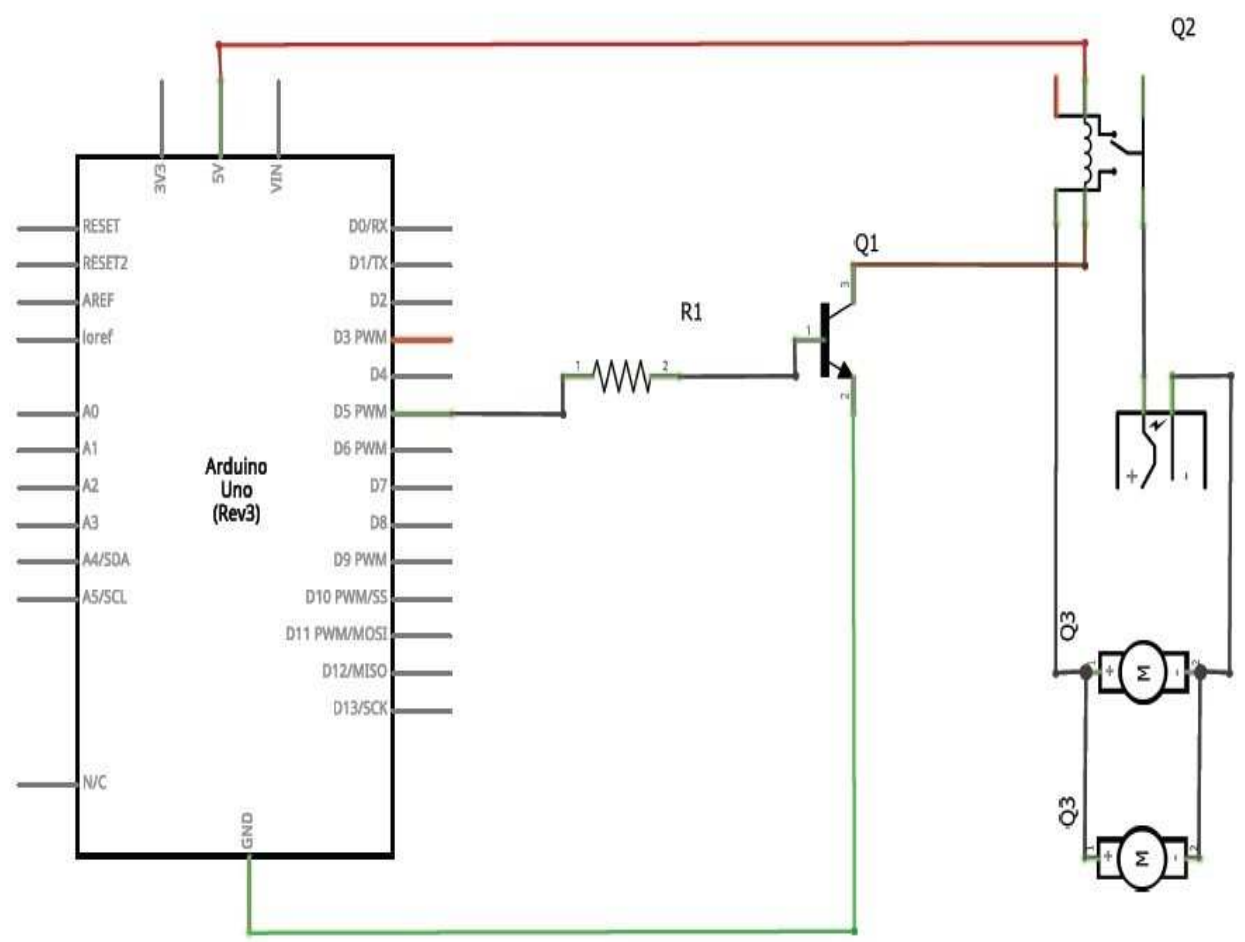

Figure 4 - Esquema do circuito para conexão dos coolers a placa Arduino. (Fonte: Os autores)

Por último, a Figura 5 ilustra o circuito referente aos botões, responsáveis pelo ajuste de temperatura e umidade programada. O botão responsável por variar a umidade está conectado ao pino 2 do Arduino e interligado ao botão de ajuste de temperatura que está conectado ao pino 4 e ao terra (GND).

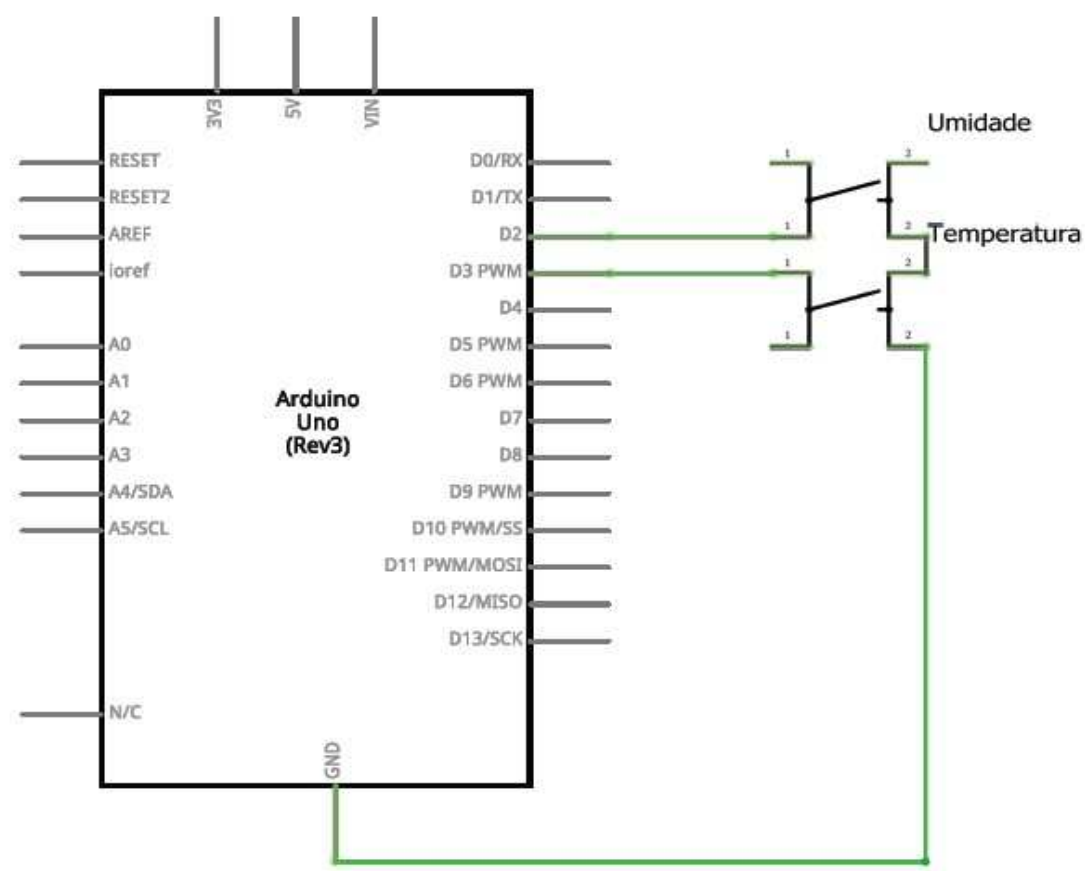

Figure 5 - Esquema do circuito para conexão dos botões de temperatura a placa Arduino. (Fonte: Os autores) 
O software Arduino foi utilizado para a implementação do código de comando. Os comandos englobam instruções que determinam que caso o valor de temperatura ou umidade seja menor do que o programado, o relé será acionado, permitindo a passagem de corrente e, consequentemente, acionará a resistência, responsável pelo aumento de temperatura e umidade do ambiente. Ao se atingir a temperatura e umidade programada, a resistência é desligada e os coolers são acionados com a finalidade de reduzir a umidade do ambiente.

Foram necessárias a inclusão das bibliotecas "DHT.h" (responsável pelo funcionamento do sensor de umidade e temperatura DHT22) e "LiquidCrystal.h" (responsável pelo funcionamento do display), para o desenvolvimento do sistema proposto (Arduino \& Cia, 2016).

Tendo a estrutura da câmara de cura por alimentação de

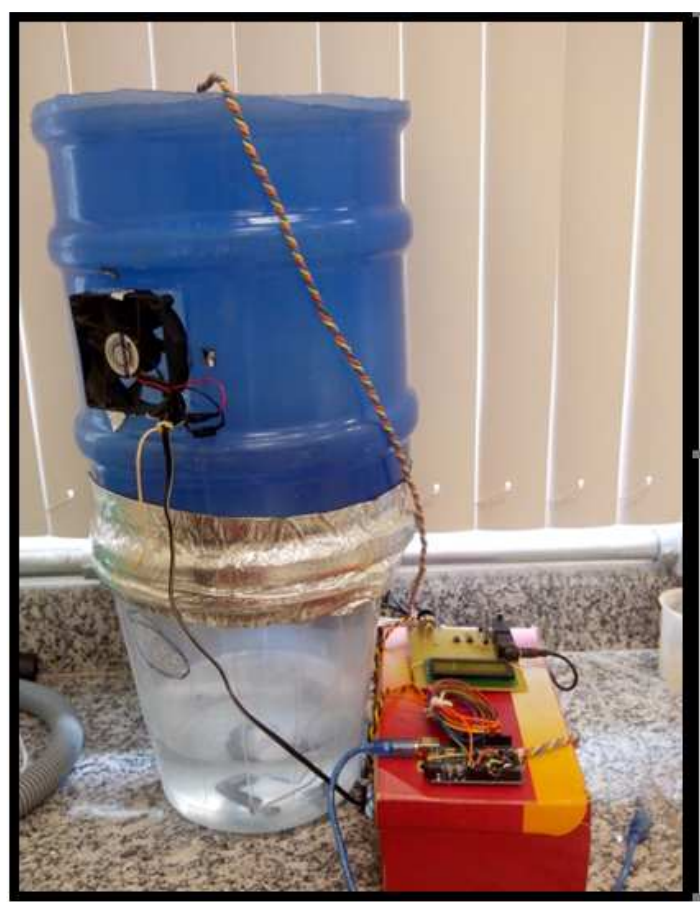

vapor construída e os códigos de comando implantados no software Arduino, foram realizados testes com o objetivo de avaliar o controle de temperatura e umidade. Os testes propostos foram realizados para valores de umidade relativa programada a $100 \%$ e a uma temperatura de $35^{\circ} \mathrm{C}$.

\section{RESULTADOS E DISCUSSÃO}

\subsection{Construção da Câmara de Cura com Alimentação a Vapor}

Seguindo a metodologia proposta no trabalho para a confecção da estrutura da câmara de cura, e utilizando os materiais indicados anteriormente, pôde-se construir a câmara de cura com alimentação a vapor como apresentado na Figura 6.

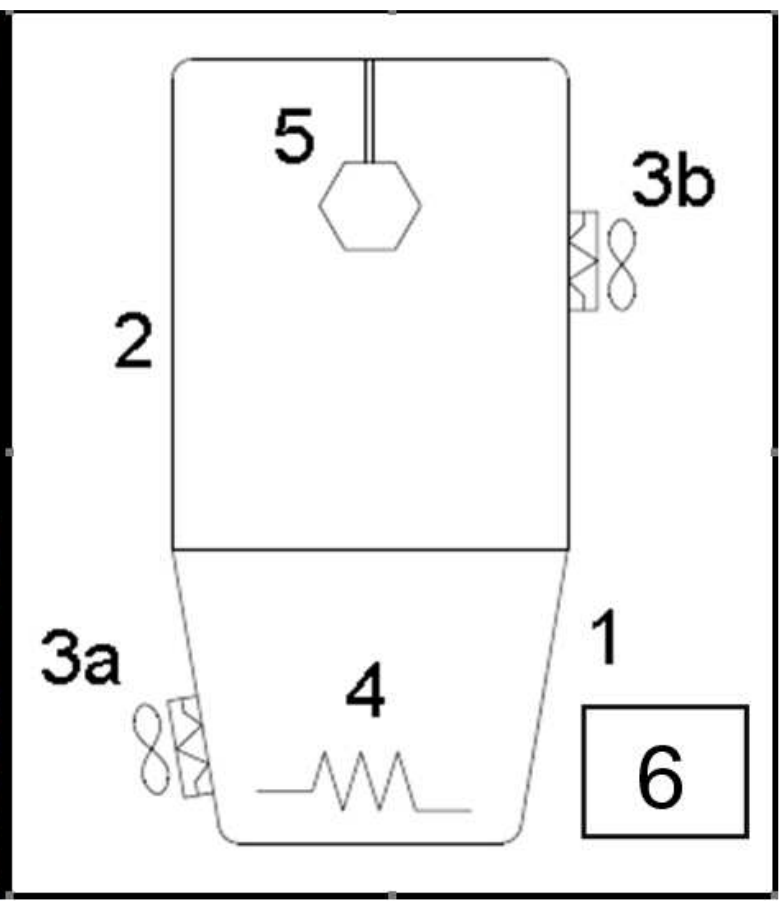

Figure 6 - Câmara de cura piloto com alimentação de vapor (1- parte cônica; 2- parte cilíndrica; 3a- Ventoinha da parte inferior; 3b- Ventoinha da parte superior; 4- Resistência Elétrica; 5- Sensor DHT22 e 6- Placa Arduino e Display). (Fonte: Os autores)

\subsection{Testes de Controle de Umidade e Temperatura}

Ao iniciar o teste proposto, a programação de $100 \%$ de umidade e $35^{\circ} \mathrm{C}$, observou-se uma grande quantidade de vapor gerado no interior da câmara de cura, onde a mesma apresentou uma umidade relativa constante de $(99,90 \pm 2,00 \%)$ praticamente durante todo o processo, como mostrado na Figura 7. Na continuação dos testes, observou-se que não era possível trabalhar com umidades abaixo de $(99,90 \pm 2,00 \%)$, devido ao ritmo máximo de funcionamento dos coolers. 


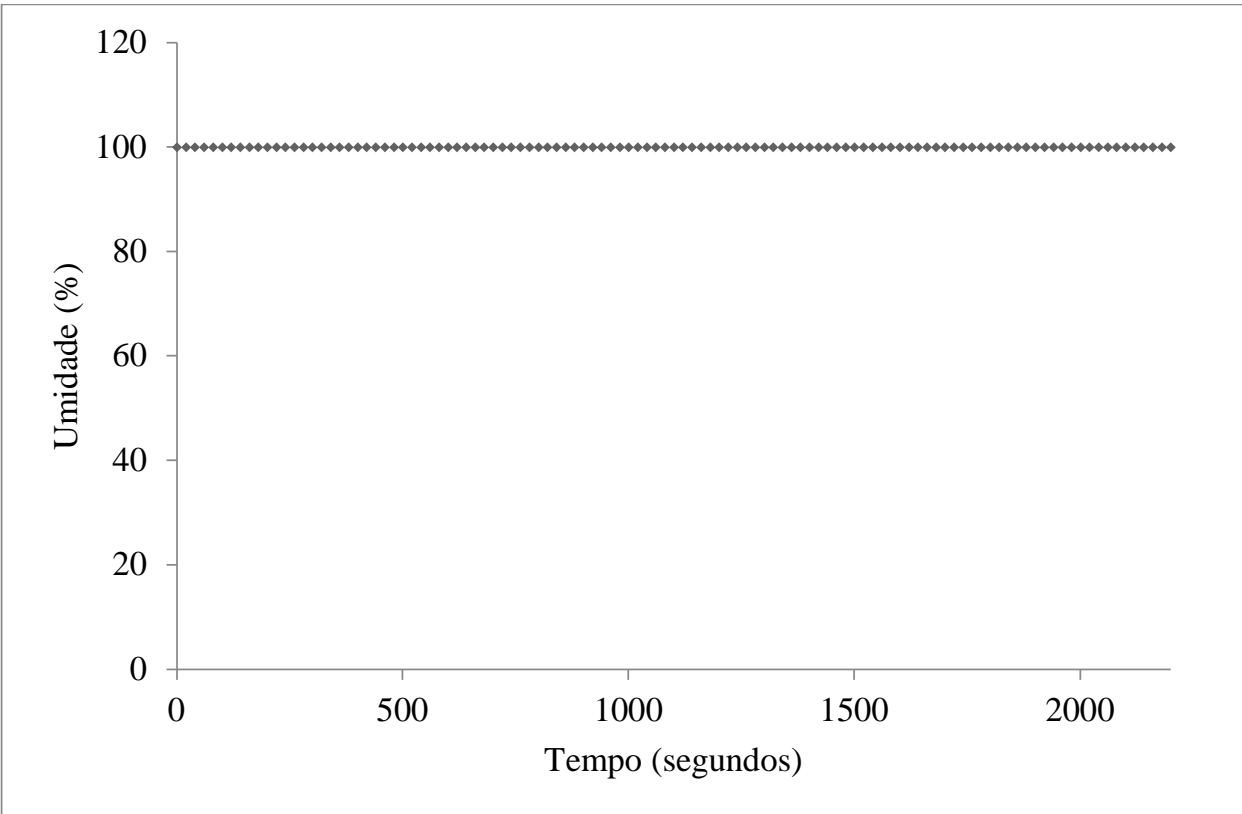

Figure 7 - Variação temporal da umidade no interior da câmara de cura durante o teste. (Fonte: Os autores)

Em relação à temperatura do interior da câmara, o controle mostrou-se satisfatório. Como podem ser observadas pela Figura 8 , as oscilações em relação ao setpoint $\left(35 \pm 0,5^{\circ} \mathrm{C}\right)$, foi mínimo no qual o valor médio de temperatura foi de 35,17 e o desvio padrão igual a 0,20 . Esses valores foram obtidos a partir das médias dos resultados realizados em triplicatas.

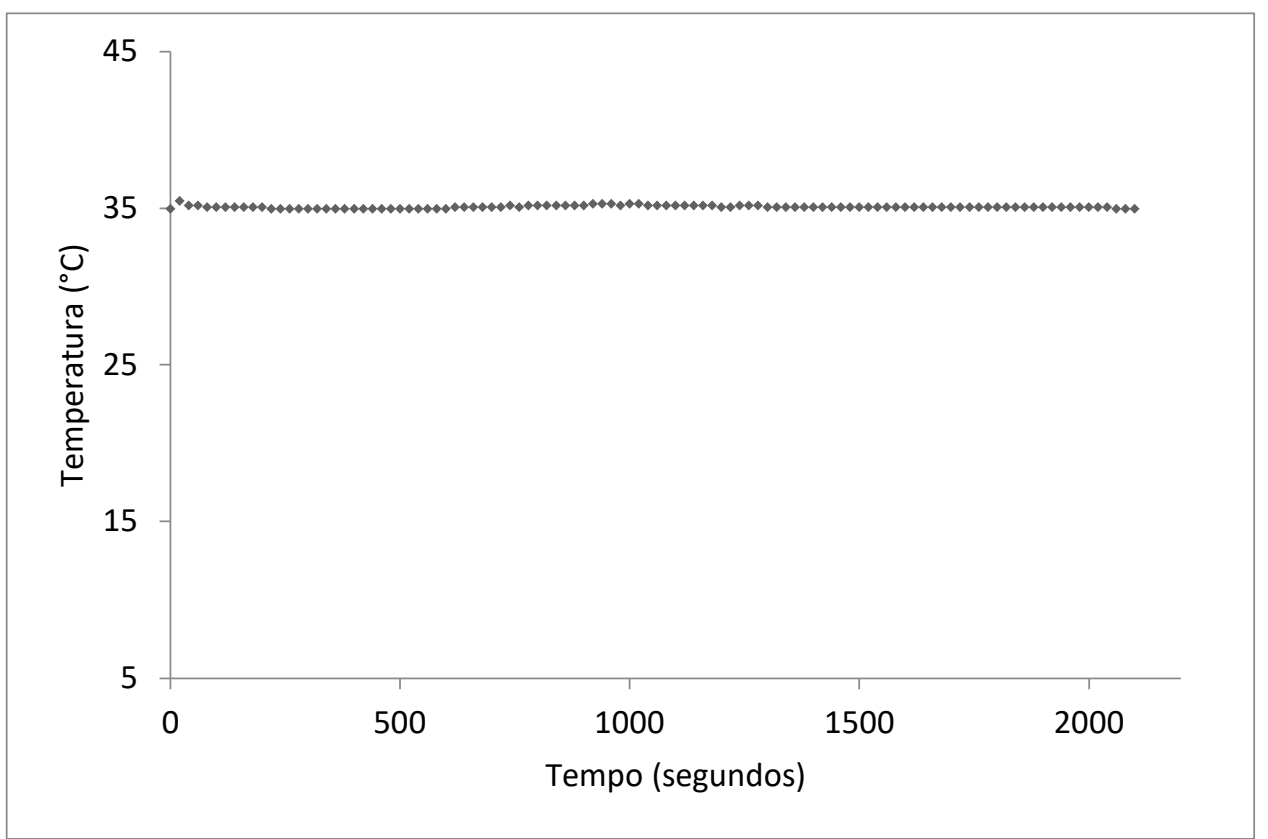

Figure 8 - Variação temporal da temperatura no interior da câmara de cura durante o teste. (Fonte: Os autores)

\section{CONCLUSÃO}

O objetivo de construir uma câmara de cura com sistema automatizado, de fácil manutenção e que fosse capaz de variar diferentes condições para a produção de mini placas de baterias chumbo-ácido foi atingido. Os resultados mostram que o hardware/software Arduino e o sensor de temperatura DHT22 atenderam aos objetivos do trabalho proposto. O uso da resistência elétrica na câmara de cura por alimentação a vapor, associado aos coolers, mostrou-se interessante quanto ao controle de temperatura. E quanto a umidade, foi possível trabalhar no valor de set-point somente em $100 \%$ de umidade, sendo então o valor no qual os coolers eram capazes de manter a variável estável. 
REFERÊ N C I A S

ARDUINO.CC. Disponível em : < https://www.arduino.cc/.>. Acessado em 22 out. 2018

FOXWORTHY, A. M. Relative-humidity/temperature relationships for saturaed salt solutions: application to lead/ acid plate curing. Journal of Power Sources, Viçosa, MG, v.22, n. 2, p. 169-173, fev. 1988.

PALMER, R. V. Estudo da sulfatação durante a formação de placas positivas empastadas de bateria de chumbo-ácido. 2008. 96 f. Dissertação (Mestrado em Engenharia e Ciências dos Materiais) - Universidade Federal do Paraná, Paraná, 2008. 